\title{
Diagnosis and Management of Statin Intolerance
}

\author{
Rodrigo Alonso ${ }^{1}$, Ada Cuevas $^{1}$ and Alberto Cafferata ${ }^{2}$ \\ ${ }^{1}$ Department of Nutrition, Clinica Las Condes, Santiago de Chile, Chile \\ ${ }^{2}$ Cardiovacular Prevention Department. Sanatorio Finochietto, Buenos Aires, Argentina
}

Statins are the main treatment for hypercholesterolemia and the cornerstone of atherosclerotic cardiovascular disease prevention. Many patients taking statins report muscle-related symptoms, one of the most important causes of statin treatment discontinuation, which is associated with an increased risk of cardiovascular events. Therefore, it is important to identify patients who are truly statin intolerant to avoid unnecessary discontinuation of this beneficial treatment. Some studies indicate that not all muscle complaints are caused by statins, and most patients can tolerate a statin upon re-challenge, down-titration of dose, or switching to another statin. In this paper, we review the definitions of statin intolerance and approaches to reducing cardiovascular risk among individuals reporting statin-associated muscle symptoms.

\section{Key words: Statins, Cardiovascular disease, Statin intolerance, Myalgia, Myopathy}

\section{Introduction}

Statins [3-hydroxy-3-methylglutaryl coenzyme A reductase (HMG-CoA) inhibitors] are the first-choice therapy for dyslipidemias and are considered the cornerstone of atherosclerotic cardiovascular disease (ASCVD) prevention ${ }^{1)}$. Their efficacy in reducing low-density lipoprotein cholesterol (LDL-C) levels and cardiovascular outcomes in primary and secondary prevention have been demonstrated in several randomized controlled trials (RCTs) comparing statins to placebo, and also high versus less intensive statin treatment ${ }^{2-6}$. Moreover, a meta-analysis of the Cholesterol Treatment Trialist Collaboration, including 26 trials with 170,000 participants followed-up during a median of 5 years, showed a $22 \%$ reduction in risk of major vascular events Risk Ratio (RR) 0.78, 95\% CI $0.76-0.80 ; p<0.0001$ per $1 \mathrm{mmol} / \mathrm{L}(-40 \mathrm{mg} / \mathrm{dL})$ in LDL-C reduction independent of baseline LDL-C levels ${ }^{7)}$. Furthermore, there was a $10 \%$ reduction in all-cause mortality (RR 0.90, 95\% CI 0.87-0.93; $p<$ 0.0001 ), principally because of fewer deaths from coronary heart disease (CHD) and other cardiac causes. Conversely, when comparing high versus less intensive statin treatment, there was a $15 \%$ reduction in major vascular events. There is no evidence of a threshold
LDL-C level suggesting that for any level of reduction in LDL-C there is a proportional reduction in the risk of cardiovascular (CV) events ${ }^{7)}$.

Although the benefit of LDL-C reduction on CV outcomes has been robustly demonstrated in RCT and meta-analysis, more than $80 \%$ of high-risk patients do not achieve recommended LDL-C targets ${ }^{1)}$. This is partly due to the use of insufficient starting doses of statins and patients' low adherencel high discontinuation rate of chronic statin treatment ${ }^{8)}$.

\section{Adherence to Statin Treatment, LDL-C Goals Achievement and Cardiovascular Disease}

Poor statin adherence, in terms of inadequate dosing and discontinuation rates, have been reported in up to $50 \%$ of patients ${ }^{8-10)}$. Data from the US reported statin adherence rates, following 2-4 years of initiation, of $25 \%$ in primary prevention and approximately $40 \%$ in patients with cardiovascular disease or after an acute myocardial infarction $(\mathrm{MI})^{8,9)}$. A recent retrospective analysis of a health database, including adult patients at very high CV risk and patients in secondary prevention, showed that only $55 \%$ were adhered to statin treatment after six months of followup and that patients with higher adherence had nearly

Address for correspondence: Rodrigo Alonso, Department of Nutrition, Clínica Las Condes, Lo Fontecilla 441, Santiago de Chile, Chile

E-mail: ralonso@clc.cl; rodrigoalonsok@gmail.com

Received: November 1, 2018 Accepted for publication: December 3, 2018

Copyright@2019 Japan Atherosclerosis Society

This article is distributed under the terms of the latest version of CC BY-NC-SA defined by the Creative Commons Attribution License. 
three times higher probability of reaching therapeutic LDL-C goals ${ }^{11)}$. Another retrospective, observational study of 7,800 US adults hospitalized for acute coronary syndrome (ACS) showed that almost $80 \%$ did not receive statin treatment before the event, and the percentage of patients receiving high intensity statin (HIS) was very low (3.4\%). This percentage increased to $13.2 \%$ during hospitalization and to $16.4 \%$ in the follow-up year. Most patients received low to moderate intensity statin doses (up to $45 \%$ in a year) ${ }^{12)}$. Colantonio et al., retrospectively analyzed approximately 58,000 Medicare patients six months and two years after their hospitalization for MI, and found that the percentage of patients using HIS with high adherence dropped from $59 \%$ to $41.6 \%$. There was a concurrent increase in the number of cases that down-titrated the dose or discontinued treatment ${ }^{13)}$. All these data suggest that there is an opportunity to improve statin utilization in adequate intensity and adherence in highrisk patients, especially after an ACS event.

Different studies, systematic reviews and metaanalyses have demonstrated the association between statin adherence and discontinuation, and the risk of CVD and mortality ${ }^{14-17)}$. A follow-up study of more than 49,000 subjects from The Netherlands, who initiated statin treatment after age 46, showed reduced adherence to statin regimens until $74 \%$ after approximately three years of follow-up, and that being adherent to statins appears to be protective against CV mortality. Completely adherent patients have 30\% lower risk of death from ASCVD compared to completely non-adherent patients ${ }^{15)}$. A nationwide study in Finland reported a 5\% reduction in CHD mortality for each $10 \%$ increase in adherence to statin use ${ }^{16)}$. A systematic review of statin discontinuation in high-risk patients reported a $67 \%$ increased risk of acute MI after statin withdrawal ${ }^{17}$.

There is no single predictor for statin discontinuation; contributing factors include patient, physician, and health system as well as mass media. A prospective cohort study in Denmark demonstrated that early statin discontinuation increased with negative statinrelated news (OR 1.09, 95\%CI 1.06-1.12) among other factors. Moreover, early discontinuation was associated with an increased risk of MI (HR 1.26; 95\%CI 1.21-1.30) and death from ASCVD (HR 1.18 ; $95 \%$ CI $1.14-1.23)^{18)}$.

\section{Statin Intolerance}

In general, statins are well tolerated. However, one of the main causes of non-adherence is the socalled "statin intolerance". Statin intolerance can be defined as any adverse event (AEs) considered unac- ceptable by the patient, and/or some laboratory abnormalities, both attributed to statin treatment and leading to its discontinuation ${ }^{19)}$. In general, discontinuation of statins due to laboratory abnormalities is less common, and most cases of discontinuation are due to muscle complaints ${ }^{20,21)}$. Side effects of statin use, other than statin-associated muscle symptoms (SAMS), which could affect a patient's quality of life, are headache, dyspepsia, nausea, alopecia, and erectile dysfunction ${ }^{22)}$.

In a cross-sectional, internet-based survey (Understanding Statin Use in America and Gaps in Patient Education, USAGE), 60\% of subjects stated that muscle pain was the primary reason for discontinuing statins and 33\% of subjects adhering to treatment considered switching to another statin ${ }^{21)}$. Statin intolerance is not mere occurrence of symptoms or laboratory abnormalities; they must occur after initiating therapy, improve with statin discontinuation, and reappear when statin is reintroduced. In addition, disorders with similar manifestations, and the so-called "nocebo effect", should be excluded ${ }^{20)}$. The nocebo effect refers to the induction or worsening of symptoms induced by sham or active therapies ${ }^{23)}$. This effect has been demonstrated recently in the GAUSS-3 trial $^{24)}$ and in the analysis of the ASCOT-LLA trial ${ }^{25}$. In the GAUSS-3 trial, 511 patients with documented intolerance to at least two statins were randomized first to atorvastatin $20 \mathrm{mg}$ daily or a placebo, with a crossover procedure after 10 weeks, to identify patients who developed muscle symptoms only with statin. After this phase, patients with intolerance only to atorvastatin were randomized to the PCSK9 inhibitor, evolocumab or ezetimibe, for 24 weeks. During the first phase, $42.6 \%$ of patients discontinued atorvastatin, but not the placebo, due to intolerable muscle symptoms, and $26.5 \%$ of patients receiving the placebo alone reported similar symptoms. In the second phase, few patients discontinued ezetimibe (6.8\%) and evolocumab $(0.7 \%)$ because of muscle symptoms. This study demonstrated that muscle complaints are not always related to statin use ${ }^{24)}$. In the analysis of the ASCOTT-LLA trial, there were no differences in muscle-related AEs, erectile dysfunction, or sleep disturbances reports between patients assigned to atorvastatin $10 \mathrm{mg}$ or placebo during the blinded randomized phase; however, during the non-blinded non-randomized phase, there were more muscle-related $\mathrm{AE}$ reports when patients and doctors knew that a statin was being used ${ }^{25)}$.

The National Lipid Association (NLA) defines statin intolerance as the inability to tolerate at least two statins, one at the lowest starting daily dose and another at any daily dose, either due to objectionable 
symptoms (real or perceived) or abnormal laboratory analysis, temporally related to statin treatment, reversible upon statin discontinuation, reproducible by rechallenge (restarting medication), and excluding other known factors ${ }^{25)}$. According to the European Atherosclerosis Society, the SAMS include the nature of muscle symptoms, increased creatine kinase (CK) levels and an association between the onset of symptoms and the initiation of statin treatment, discontinuation of therapy, and re-challenge ${ }^{26}$. Recently, the LusoLatin American Consortium consensus paper defined statin intolerance with some pharmacologic, symptomatic, and etiologic criteria ${ }^{27}$. They defined statin intolerance as the inability to tolerate at least two statins at any dose or inability to tolerate increasing doses, and symptoms are not attributable to drug-drug interactions or conditions known to increase statin intolerance. Symptomatic criteria are intolerable muscle symptoms (pain, weakness or cramps with or without CK changes) or severe myopathy, and they must appear in the first 12 weeks after initiating treatment or dose increase. Symptoms must improve or disappear within four weeks of statin discontinuation ${ }^{27)}$.

Data from RCTs have shown that some AEs attributed to statins are not caused by them and that statin treatment is generally as well tolerated as placebo $^{28,29)}$. In a systematic review of 26 clinical trials, $12.7 \%$ of subjects treated with statins and $12.4 \%$ with placebo referred to muscle complaints ${ }^{29)}$.

It is important to identify patients who are truly statin intolerant to reduce unnecessary discontinuation of therapy in patients who can benefit from avoiding the subsequent increase in $\mathrm{CV}$ risk.

A retrospective analysis of 105,329 Medicare beneficiaries who began statin treatment after hospitalization for MI found that $1.65 \%$ of beneficiaries were statin intolerant and had a higher rate of recurrent MI and CHD events (43\%) compared to high statin adherent beneficiaries. The multivariateadjusted hazard ratio for recurrent $\mathrm{MI}$ was 1.50 (95\%CI 1.30-1.73) and for CHD events was 1.51 (95\% CI 1.34-1.70). No increase in all-cause mortality was observed ${ }^{30)}$.

\section{Statin-Associated Muscles Symptoms. Clinical Presentation}

Effective treatment with atorvastatin $40 \mathrm{mg}$ daily during five years in 10,000 individuals would cause five cases of myopathy and 50-100 cases of muscle pain or weakness according to one estimate ${ }^{28)}$. The most common form of SAMS is myalgia that sometimes is undistinguishable from other causes. Myalgia associated with statins is usually symmetrical and affects large muscle groups (shoulder and pelvic girdle, arms and legs). Other complaints are cramps, muscle weakness, and tenderness or heaviness during exercise. Frequently, patients report mild to moderate muscle weakness or pain that occurs without a substantial increase in CK levels ${ }^{31)}$. In the presence of intolerable muscle pain, serum CK should be measured immediately. Prevalence of myalgia ranges from $1 \%-5 \%$ in RCTs to $29 \%$ in observational studies ${ }^{32,33)}$. This difference in prevalence can be partly explained in statin RCTs patients with a history of SAMS or who presented symptoms during the initial statin run-in phase (in some trials), or who had comorbidities or were taking medication that could have interacted with statins were excluded.

The NLA recently updated the classification of SAMS as myalgia, myopathy, myositis, and myonecrosis (including rhabdomyolysis) ${ }^{33)}$. Myopathy has been defined as muscle weakness (not attributed to pain) and is not necessarily associated with elevation in CK levels. Myositis describes muscle inflammation associated with pain and tenderness to palpation, and myonecrosis with increased $\mathrm{CK}$ levels varying from mild ( $>3$-fold than baseline CK) to severe ( $\geq 50$-fold) adjusted for age, race, and sex, with or without pain. If myoglobinuria and/or increase in serum creatinine $>0.5 \mathrm{mg} / \mathrm{dL}$ are present, the diagnosis is rhabdomyolysis, the most severe form of myonecrosis. In this update, a statin-associated myalgia index is proposed based on the results of the STOMP (Effects of Statins on Skeletal Muscle Function and Performance Trial) study ${ }^{34)}$. This double-blind trial aimed to determine the incidence of statin-associated symptoms in statinnaïve subjects using a standardized definition. Patients were randomized to atorvastatin $80 \mathrm{mg}$ or placebo and were followed-up through a phone-call every two weeks. A two-fold increase in myalgia in atorvastatin 80 users, compared to placebo, was observed $(9.4 \%$ vs. $4.6 \%, p=0.054)$. The index proposed by the 2014 NLA update classifies muscle complaints as probable, possible, and unlikely related to statin-based on regional distribution and symmetry, temporal association with initiating statin treatment, changes following withdrawal (de-challenge), or reoccurrence after restarting the same statin ${ }^{33)}$. This index has not been validated yet in a prospective study; however, it is a good tool to estimate the probability of association of muscle complaints with statins.

In the European Consensus Statement, all muscle complaints, including pain, cramps, and weakness, were grouped as muscle symptoms and classified according to CK level elevation ${ }^{26}$. Muscle symptoms with CK levels $>10 \mathrm{x}$ ULN are usually known as myositis or myopathy (by regulatory agencies). The inci- 
dence is 1 per 10,000 per year with some variation among different statins, statin doses, and other factors that can increase blood statin levels. Rhabdomyolysis is a rare disorder (1 per 100,000 per year) defined as CK levels $>40 \mathrm{x}$ ULN in the presence of myoglobinuria and renal failure. For this consensus statement, monitoring CK levels is not recommended due to the low incidence of CK elevation during statin treatment, except in the presence of muscle symptoms clearly associated with statins, considering symptoms change with cessation, restarting the same statin, or starting a new statin.

Muscle symptoms and CK elevations occur more frequently in physically active individuals during and after exercise. An eight-year follow-up of 22 professional athletes with familial hypercholesterolemia (FH), showed that only six tolerated at least one statin and that only two tolerated a change to any other statin $^{35)}$. In another study involving marathon runners, CK levels measured $24 \mathrm{~h}$ after the race and adjusted for plasma changes, were significantly higher in statin users than non-statin users, especially among older athletes ${ }^{36)}$. No relationship between statin potency and differences in CK levels was observed.

Significant reductions in energy and exertional fatigue have been reported in a randomized six-month study of 1,016 healthy individuals receiving simvastatin $20 \mathrm{mg}$ or pravastatin $40 \mathrm{mg}$ compared to placebo. The effect was most striking in women and in patients taking simvastatin ${ }^{37)}$.

\section{Statin Intolerance in Children}

Different meta-analyses and systematic reviews of RCTs of statins up to two years in children/adolescents (8-18 years) have confirmed that the risk of AEs is very low, and that the most common AEs experienced by children are headache, abdominal complaints, and myalgia. They are transient, and there are no differences according to the type and dose of statin. There were no changes in transaminases or CK levels between those receiving statins or placebo, except for lovastatin ${ }^{38-40)}$. There was no demonstrable effect of statins on sexual development and maturation. Longterm follow-up of children treated with atorvastatin or pravastatin have confirmed these previous findings. An open-label multicenter, prospective study in children aged 6-15 years with $\mathrm{FH}$, who used atorvastatin up to $40 \mathrm{mg}$ daily over three years, showed that most AEs were of mild or moderate intensity. Only $2.2 \%$ of children discontinued medication and $8.9 \%$ reduced the dose or discontinued temporarily due to treatment related $\mathrm{AEs}^{41)}$. Another study assessing tolerability and self-reported adherence to statin treatment after 10 years of treatment in $\mathrm{FH}$ children demonstrated that $82 \%$ continued lipid-lowering treatment, with a high self-reported adherence (79\%), and that only $1.5 \%$ discontinued treatment due to AEs. Muscle complaints (9\%) and gastrointestinal symptoms (7\%) were the most common side effects reported by children, and no elevations in liver enzymes or rhabdomyolysis occurred $^{42)}$.

In the UK National Pediatric register, after a mean follow-up of 2.7 years, only $53 \%$ of children continued statin treatment varying significantly by age group (17\% from 5 to 10 years, $57 \%$ from 10 to 15 years, and $73 \%>15$ years), and statin intolerance in children or their parent explain only $2 \%$ of cases not initiating statins ${ }^{43)}$. In the SAFEHEART registry in Spain, 68\% of children continued statin treatment (with or without ezetimibe) after a mean follow-up of 4.7 years. Adherence to therapy was very good, and < $4 \%$ discontinued taking statin temporarily, but it was not related to AEs. No muscle complaints, increased CK levels, or elevated liver enzymes were reported. No difference in the age of menarche was observed between girls taking or not taking statins. The LDL-C target below $130 \mathrm{mg} / \mathrm{dL}$ improved from $20 \%$ to $42 \%$ during follow-up ${ }^{44)}$. In conclusion, AEs in children taking statins are rare and generally transient. Only a minority discontinued taking statin because of intolerance. To avoid unnecessary discontinuation of statin treatment in high-risk children, like those with $\mathrm{FH}$, it is important to raise awareness of the efficacy and safety of long-term statin treatment in patients, particularly their parents.

\section{Management of Statin Intolerance}

To avoid premature discontinuation of statin treatment due to muscle complaints in high-risk patients, it is important to emphasize to the patient the demonstrated cardiovascular benefits of statins and to explain that myopathy is a very rare AE. When a patient on statin develops muscle symptoms, it is necessary to assess whether the symptoms are attributable to statin or not by measuring CK levels, evaluating risk factors for intolerance or other causes of the symptoms (Table 1), and determining the effect of temporary withdrawal of statin followed by re-challenge.

Lifestyle changes, including diet, exercise, and smoking cessation, are important for reducing cholesterol levels and improving other cardiovascular risk factors, thereby reducing cardiovascular risk ${ }^{1)}$. LDL-C levels can be reduced by $10 \%$ by adding plant sterols and stanols to a healthy diet ${ }^{45)}$. There is no evidence that vitamin D and coenzyme Q10 supplements would prevent or reduce muscle symptoms; therefore, 
Table 1. Risk factors associated with statin-associated muscle symptoms

\section{Female gender ${ }^{53}$}

Advanced age (>75 years). Statins are generally well tolerated in the elderly. In RCTs there were no differences in muscle symptoms among patients treated with statin or placebo and also in study drug discontinuation; however, there are different factors and conditions that can increase adverse events in the elderly (decrease in lean body mass, reduction in albumin levels, decreased glomerular filtration rate, etc ${ }^{54)}$.

Abdominal obesity and metabolic syndrome ${ }^{55,56)}$

Frailty

Vitamin D deficiency: Low vitamin D levels are associated with myalgia in patients receiving statin therapy; however, there is no evidence of benefit from Vitamin D supplementation, even in patients with insufficient levels to prevent

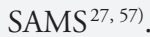

Alcohol consumption: There is risk over $30 \mathrm{~g} / \mathrm{d}$ in men and $20 \mathrm{~g} / \mathrm{d}$ in women ${ }^{55)}$

Excessive physical activity ${ }^{35}$

Not controlled hypothyroidism ${ }^{58}$

Chronic Kidney Disease: Although a meta-analysis showed little or no risks of myalgia (RR0.99, CI 0.94-1.04) and elevated CK levels (RR 1.11, CI 0.80-1.04), precaution is necessary when statins are used in this condition ${ }^{59)}$.

Liver disease

Metabolic muscle disorders

Family history of statin intolerance and personal history of intolerance to other statins and lipid-lowering therapies

Drugs affecting statin metabolism increasing their plasma levels ${ }^{60)}$ (inhibitors of CYP3A4: Macrolides, Fluoxetine, Verapamil, Protease inhibitors, grape fruit, etc.), lovastatin; inhibitors CYP2C9: ketoconazole, Fluconazole, Fluoxetine, Amiodarone, etc.; inhibitors of organic anion transporting peptide 1B1: gemfibrozil)

Adapted from references 26, 27, 60

they are not indicated for treating SAMS $26,27,33)$.

Different statin-based approaches have been proposed to manage muscle symptoms, such as switching to a different statin, lowering the dose (de-challenge) or frequency (intermittent dosages), or re-challenging with the same statin (Table 2). If the new regime is tolerated, doses can be up-titrated slowly to achieve LDL-C goals with minimal or no muscle complaints. For patients who do not tolerate statins on a daily basis, alternate day or twice-weekly dosing is a good option. Rosuvastatin and atorvastatin have longer half-lives, permitting their use on a non-daily regime. Different studies have shown that administering rosuvastatin once or twice-weekly in patients with previous AEs produces a modest reduction (up to 26\%) in LDL-C levels, but it is tolerated by more than $70 \%$ of patients ${ }^{46-48)}$. It is important to highlight that the cardiovascular benefit of this approach has not been demonstrated. A recent cross-sectional analysis of 10,138 current and former statin users from the USAGE survey showed that the most common suggestions to patients who reported muscle symptoms to their pro- viders were to switch to another statin in approximately $34 \%$ of cases, stop taking statin in approximately $16 \%$, do nothing with statin and its dose, but monitor symptoms in $12 \%$, and reduce the dose in approximately $10 \%$. Fewer than $10 \%$ were advised to consider alternative options like vitamin $\mathrm{D}$ or coenzyme Q10 supplements ${ }^{49)}$. All of these strategies are recommended by different scientific societies with the exception of vitamin D and Coenzyme Q10 supplements $^{20,26,33)}$

If statins are not tolerated at all, other lipid-lowering drugs, in monotherapy or in addition to the maximum tolerated statin dose, are recommended to achieve LDL-C goals ${ }^{22,27,33)}$. The first option is adding ezetimibe to a lower statin dose or ezetimibe monotherapy that decreases LDL-C by $20 \%$ and is usually well tolerated. Adding fibrates or resins may be considered if ezetimibe is not enough to achieve LDL-C goals. Reduction in LDL-C level by fibrates is around $15 \%$ and its cardiovascular benefit has been demonstrated in post-hoc analysis of RCTs in hypertriglyceridemia patients. However, using gemfibrozil 
Table 2. Therapeutic options in patients intolerant to statins

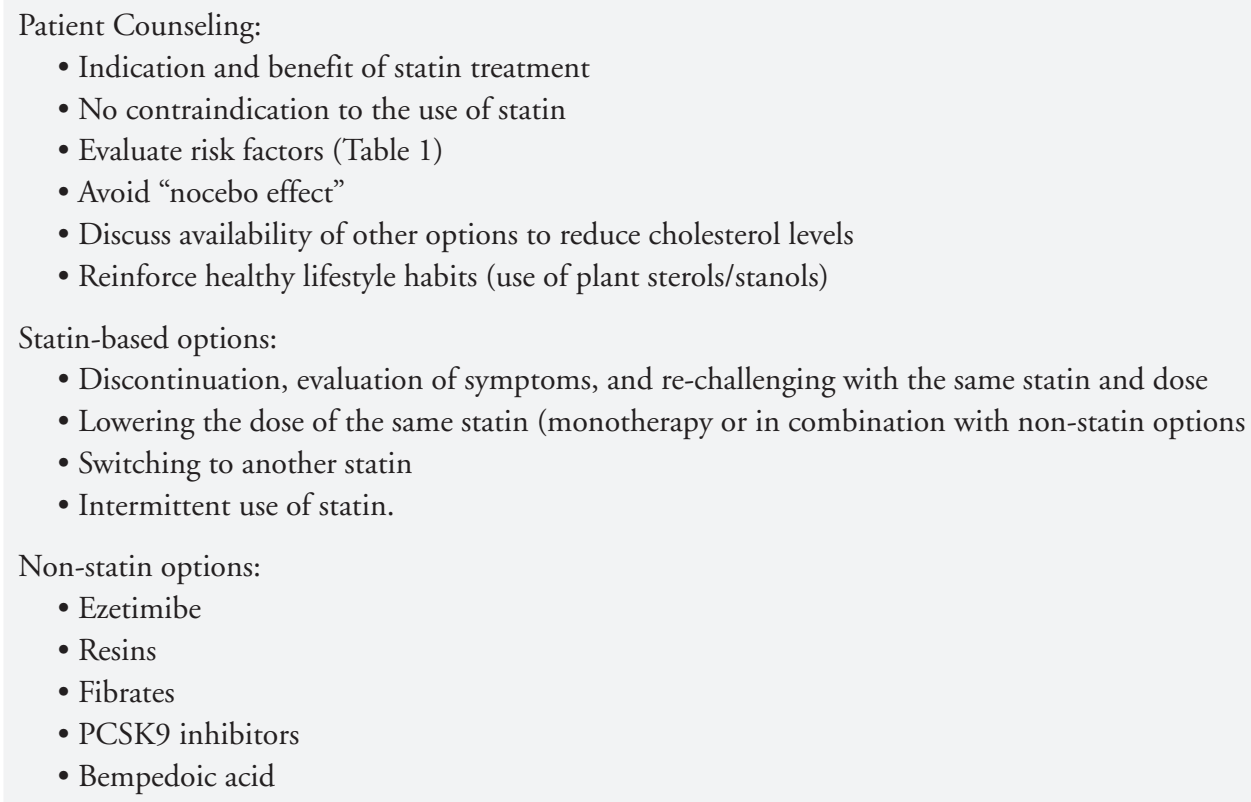

Supplementation of Vitamin D: There is no evidence of benefit in the prevention of SAMS; however, it is recommended to treat in deficient individuals.

Supplementation of Coenzyme Q10: No evidence of benefit

must be avoided with statins because of the risk of myopathy; other fibrates with less interaction profile, like fenofibrate, are preferable.

PCSK9 inhibitors have been approved in the USA and Europe for patients who are statin intolerant. Studies have shown LDL-C reductions $>50 \%$ for alirocumab and evolocumab, and cardiovascular benefit has been demonstrated for both agents. In the ODYSSEY ALTERNATIVE trial comparing alircoumab to ezetimibe in patients intolerant to two or more statins, using a statin re-challenge arm (atorvastatin 20), alirocumab was associated with lower rate of muscle symptoms compared with atorvastatin ${ }^{50)}$. Interestingly, $46 \%$ of patients in the re-challenge arm reported muscle AEs, and 22\% discontinued taking statin, implying that many patients with a history of statin intolerance may tolerate statins in future. Moreover, muscle $\mathrm{AE}$ rates decreased significantly when patients entered the open-label treatment period and they knew that they were not receiving statin treatment. In the GAUSS-2 randomized trial, comparing evolocumab and ezetimibe in patients with statin intolerance, the PCSK9 inhibitor resulted in significantly greater LDL-C reduction with no significant muscle-related side effects ${ }^{51)}$. The GAUSS-3 trial showed similar rates of muscle symptoms in ezetimibe treated patients $(28.8 \%)$ and in evolocumab-treated patients $(20.7 \%)$, but medication was stopped for muscle symptoms in almost $7 \%$ of patients receiving ezetimibe compared to $0.7 \%$ receiving evolocumab ${ }^{24)}$.

Recently, a phase 3 trial with Bempedoic acid $180 \mathrm{mg}$ daily, added to background ezetimibe in 269 statin intolerant patients, resulted in a placebo-corrected mean change in LDL-C of $-28.5 \%$ after 12 weeks of treatment. The lowering effect was greater among patients with no statin or background therapy compared to patients on a low statin dose $(34.7 \%$ vs. $20.5 \% ; p=0.003$, respectively) ${ }^{52)}$.

\section{Conclusions}

Since the time statins were developed, they became the main medication against ASCVD. Symptom onset associated with muscles and other AEs may affect the long-term adherence to statin treatment; however, these effects are generally infrequent and do not cause chronic damage. Due to the high discontinuation rate of statin treatment, it is important to gather all the information related to AEs to avoid unnecessary withdrawal of the therapy and prevent the subsequent increase in cardiovascular risk. 


\section{Conflics of Interest}

The authors declare No conflicts of interest.

\section{References}

1) Piepoli M, Hoes A, Agewall S, Albus C, Brotons C, Catapano A, Cooney MT, Corrà U, Cosyns B, Deaton C, Graham I, Hall MS, Hobbs FDR, Løchen ML, Löllgen H, Marques-Vidal P, Perk J, Prescott E, Redon J, Richter DJ, Sattar N, Smulders Y, Tiberi M, van der Worp HB, van Dis I, Verschuren WMM, Binno S; ESC Scientific Document Group. 2016 European Guidelines on cardiovascular disease prevention in clinical practice. The Sixth Joint Task Force of the European Society of Cardiology and other Societies on Cardiovascular Disease Prevention in Clinical Practice (constituted by representatives of 10 societies and by invited experts). Eur Heart J, 2016; 37: 2315-2381

2) Scandinavian Simvastatin Survival Group. Randomised Trial of cholesterol lowering in 4444 patients with coronary heart disease: The Scandinavian Simvastatin Survival Study (4S). The Lancet, 1994; 344: 1383-1389

3) Lewis SJ, Moye LA, Sacks FM, Johnstone DE, Timmis G, Mitchell J, Limacher M, Kell S, Glasser SP, Grant J, Davis BR, Pfeffer MA, Braunwald E. Effect of pravastatin on cardiovascular events in older patients with myocardial infarction and cholesterol levels in the average range. Results of the Cholesterol and Recurrent Events (CARE) trial. Ann Intern Med, 1998; 129: 681-689

4) Heart Protection Study Collaborative Group. Effects of cholesterol-lowering with simvastatin on stroke and other major vascular events in 20536 people with cerebrovascular disease or other high-risk conditions. Lancet, 2004; 363: 757-767

5) LaRosa J, Grundy S, Waters D, Shear C, Barter P, Fruchart JC, Gotto AM, Greten H, Kastelein JJ, Shepherd J, Wenger NK; Treating to New Targets (TNT) Investigators. Intensive Lipid Lowering with atorvastatin in patients with stable coronary disease. N Engl J Med, 2005; 352: 1425-1435

6) Ridker PM, Danielson E, Fonseca FA, Genest J, Gotto AM Jr, Kastelein JJ, Koenig W, Libby P, Lorenzatti AJ, MacFadyen JG, Nordestgaard BG, Shepherd J, Willerson JT, Glynn RJ; JUPITER Study Group. Rosuvastatin to prevent vascular events in men and women with elevated C-reactive protein. N Engl J Med, 2008; 359: 2195-2207

7) Cholesterol Treatment Trialists C, Baigent C, Blackwell L, Emberson J, Holland LE, Reith C, Bhala N, Peto R, Barnes EH, Keech A, Simes J, Collins R. Efficacy and safety of more intensive lowering of LDL cholesterol: a meta-analysis of data from 170,000 participants in 26 randomised trials. Lancet, 2010; 376: 1670-1681

8) Gislason GH, Rasmussen JN, Abildstrøm SZ, Gadsbøll N, Buch P, Friberg J, Rasmussen S, Køber L, Stender S, Madsen M, Torp-Pedersen C. Long-term compliance with beta-blockers, angiotensin-converting enzyme inhibitors, and statins after acute myocardial infarction. Eur Heart J, 2006; 27: 1153-1158

9) Ellis JJ, Erickson SR, Stevenson JG, Bernstein SJ, Stiles
RA, Fendrick AM. Suboptimal statin adherence and discontinuation in primary and secondary prevention populations. J Gen Intern Med, 2004; 19: 638-645

10) Blackburn DF, Dobson RT, Blackburn JL, Wilson TW, Stang MR, Semchuk W. Adherence to statins, beta-blockers and angiotensin-converting enzyme inhibitors following a first cardiovascular event: a retrospective cohort study. Can J Cardiol, 2005; 21: 485-488

11) Guglielmi V, Bellia A, Pecchioli S, Della-Morte D, Parretti D, Cricelli I, Medea G, Sbraccia P, Lauro D, Cricelli C, Lapi F. Effectiveness of adherence to lipid lowering therapy on LDL-cholesterol in patients with very high cardiovascular risk: A real-world evidence study in primary care. Atherosclerosis, 2017; 263: 36-41

12) Boklage S, Malangone-Monaco E, Lopez-Gonzalez L, Ding Y, Henriques C, Elassal J. Statin utilization patterns and outcomes for patients with acute coronary síndrome during and following inpatients admissions. Cardiovasc Drugs Ther, 2018; 32: 273-280

13) Colantonio L, Huang L, Monda KL, Bittner MC, Taylor TM, Glasser SP, Muntner P, Rosenson RS. Adherence to high-intensity statins following a myocardial infarction hospitalization among Medicare beneficiaries. JAMA Cardiol, 2017; 2: 890-895

14) De Vera M, Bhole V,Burns L, Lacaille D. Impact of statin adherence on cardiovascular disease and mortality outcomes: a systematic review. Br J Clin Pharmacol, 2014; 78: 684-698

15) Bijlsma M, Vansteelandt S, Janssen F, Hak E. The effect of adherence to statin therapy on cardiovascular mortality: quantification of unmeasured bias using falsification endpoints. BMC Public Health, 2016; 16: 303. doi: $10.1186 /$ s12889-016-2986-2990

16) Haukka J, Niskanen L, Partonen T, Lönnqvist J, Thihonen J. Statin usage and all-cause and disease-specific mortality in a nationwide study. Pharmacoepidemiol Drug Saf, 2012; 21: 61-69

17) Gomez Sandoval YH, Braganza MV, Daskalopoulou SS. Statin discontinuation in high-risk patients: a systematic review of the evidence. Curr Pharm Des, 2011; 17: 36693689

18) Nielsen SF, Nordestgaard BG. Negative statin-related news stories decrease statin persistence and increase myocardial infarction and cardiovascular mortality: a nationwide prospective cohort study. Eur Heart J, 2016; 37: 908-916

19) Stulc T, Ceska R, Gotto Jr A. Statin intolerance: The clinician's perspective. Curr Atheroscler Rep, 2015; 17: 69. Doi: $10.1007 /$ s11883-015-0552-3

20) Guyton JR, Bays HE, Grundy SM, Jacobson TA, The National Lipid Association Statin Intolerance Panel. An assessment by the Statin Intolerance Panel: 2014 update. J Clin Lipidol, 2014; 8: S72-S81

21) Wai MY, Ito MK, Cohen JD, Brinton EA, Jacobson TA. Predictors of statin adherence, switching, and discontinuation in the USAGE survey: understanding the use of statins in America and gaps in patient education. J Clin Lipidol, 2013; 7: 472-484

22) Banach M, Rizzo M, Toth PP, Farnier M, Davidson MH, Al-Rasadi K, Aronow WS, Athyros V, Djuric DM, Ezhov MV, Greenfield RS, Hovingh GK, Kostner K, Serban C, 
Lighezan D, Fras Z, Moriarty PM, Muntner P, Goudev A, Ceska R, Nicholls SJ, Broncel M, Nikolic D, Pella D, Puri R, Rysz J, Wong ND, Bajnok L, Jones SR, Ray KK, Mikhailidis DP. Statin intolerance-an attempt at a unified definition. Position paper from an International Lipid Expert Panel. Arch Med Sci, 2015; 11: 1-23

23) Planès $S$, Villier $C$, Mallaret $M$. The nocebo effect of drugs. Pharmacol Res Perspect, 2016; 4: e00208

24) Nissen SE, Stroes E, Dent-Acosta RE, Rosenson RS, Lehman SJ, Sattar N, Preiss D, Bruckert E, Ceška R, Lepor N, Ballantyne CM, Gouni-Berthold I, Elliott M, Brennan DM, Wasserman SM, Somaratne R, Scott R, Stein EA; GAUSS-3 Investigators. Efficacy and tolerability of evolocumab vs ezetimibe in patients with musclerelated statin intolerance: the GAUSS-3 randomized clinical trial. JAMA, 2016; 315: 1580-1590

25) Gupta A, Thompson D, Whitehouse A, Collier T, Dahlof B, Poluter N, Collins R, Seveer P; ASCOR investigators. Adverse events associated with unblinded, but not with blinded, statin therapy in the Anglo-Scandinavian Cardiac Outcomes Trial-Lipid-Lowering Arm (ASCOT-LLA): a randomised double-blind placebo-controlled trial and its non-randomised non-blind extension phase. Lancet, 2017; 389: 2473-2481

26) Stroes ES, Thompson PD, Corsini A, Vladutiu GD, Raal FJ, Ray KK, Roden M, Stein E, Tokgözoğlu L, Nordestgaard BG, Bruckert E, De Backer G, Krauss RM, Laufs U, Santos RD, Hegele RA, Hovingh GK, Leiter LA, Mach F, März W, Newman CB, Wiklund O, Jacobson TA, Catapano AL, Chapman MJ, Ginsberg HN; European Atherosclerosis Society Consensus Panel. Statin-associated muscle symptoms: impact on statin therapy-European Atherosclerosis Society Consensus Panel Statement on Assessment, Aetiology and Management. Eur Heart J, 2015; 36: 1012-1022

27) Sposito A, Rocha Faria J, de Carvalho L, Lorenzatti A, Cafferata A, Elikir G, Esteban E, Morales Villegas EC, Bodanese LC, Alonso R, Ruiz AJ, Rocha VZ, Faludi AA, Xavier HT, Coelho OR, Assad MH, Izar MC, Santos RD, Fonseca FA, Mello E Silva A, Silva PM, Bertolami MC; on behalf of the Luso-Latin American Consortium on Statin-Associated Muscle Symptoms. Statin-associated muscle symptoms: position paper from the Luso-Latin America Consortium. Curr Med Res Opin, 2017; 33: 239-251

28) Collins R, Reith C, Emberson J, Armitage J, Baigent C, Blackwell L, Blumenthal R, Danesh J, Smith GD, DeMets D, Evans S, Law M, MacMahon S, Martin S, Neal B, Poulter N, Preiss D, Ridker P, Roberts I, Rodgers A, Sandercock P, Schulz K, Sever P, Simes J, Smeeth L, Wald N, Yusuf S, Peto R. Interpretation of the evidence for the efficacy and safety of statin therapy. Lancet, 2016; 388: 2532-2561

29) Ganga HV, Slim HB, Thomnpson PD. A systematic review of statin-induced muscle problems in clinical trial. Am Heart J, 2014; 168: 6-15

30) Serban MC, Colantonio L, Manthripragada A, Monda K, Bittner V, Banach M, Chen L, Huang L, Dent R, Kent ST, Muntner P, Rosenson RS. Statin intolerance and risk of coronary heart events and all-cause mortality following myocardial infarction. JACC, 2017; 69: 1386-1395
31) Alfirevic A, Neely D, Armitage J, Chinoy H, Cooper RG, Laaksonen R, Carr DF, Bloch KM, Fahy J, Hanson A, Yue QY, Wadellus M, Maitland-van Der Zee AH, Voora D, Psaty BM, Palmer CN, Pirmohamed M. Phenotype standardization for statin-induced myotoxicity. Clin Pharmacol Therapeut, 2014; 96: 470-476

32) Bruckert E, Hayem G, Dejager S, Yau C, Begaud B. Mild to moderate muscular symptoms with high-dosage statin therapy in hyperlipidemic patients - the PRIMO study. Cardiovasc Drugs Ther, 2005; 19: 403-414

33) Rosenson RS, Baker SK, Jacobson TA, Kopecky SL, Parker BA. An assessment by the Statin Muscle Safety Task Force: 2014 update. J Clin Lipidol, 2014; 8: S58S71

34) Parker BA, Capizzi JA, Grimaldi AS, Clarkson PM, Cole SM, Keadle J, Chipkin S, Pescatello LS, Simpson K, White CM, Thompson PD. Effect of statins on skeletal muscle function. Circulation, 2013; 127: 96-103

35) Sinzinger H, O'Grady J. Professional athletes suffering from familial hypercholesterolaemia rarely tolerate statin treatment because of muscular problems. Br J Clin Pharmacol, 2004; 57: 525-528

36) Parker BA, Augeri AL, Capizzi JA, Ballard KD, Troyanos C, Baggish AL, D'Hemecourt PA, Thompson PD. Effect of statins on creatin kinase levels before and after a marathon run. Am J Cardiol, 2012; 109: 282-287

37) Golomb BA, Evans MA, Dimsdale JE, White HL. Effects of statins on energy and fatigue with exertion: results from a randomized controlled trial. Arch Intern Med, 2012; 172: 1180-1182

38) Arambepola C, Farmer AJ, Perera R, Neils HA. Statin treatment for children and adolescents with heterozygous familial hypercholesterolaemia: a systematic review and meta-analysis. Atherosclerosis, 2007; 195: 339-347

39) Avis HJ, Vissers MN, Stein EA, Wijburg FA, Trip MD, Kastelein JJ, Hutten BA. A systematic review and metaanalysis of statin therapy in children with familial hypercholesterolemia. Arterioscler Thromb Vasc Biol, 2007; 27: 1803-1810

40) Vuorio A, Kuoppala J, Kovanen PT, Humphries SE, Tonstad S, Wiegman A, Drogari E. Statins for children with familial hypercholesterolemia. Cochrane Database Syst Rev, 2017; doi:10.1002/14651858

41) Langslet G, Breazna A, Drogari E. A 3-year study of atorvastatin in children and adolescents with heterozygous familial hypercholesterolemia. J Clin Lipidol, 2016; 10: 1153-1162

42) Braamskamp MJ, Kusters DM, Avis HJ, Smets EM, Wijburg FA, Kastelein JJ, Wiegman A, Hutten BA. Longterm treatment in children with familial hypercholesterolemia: more insight into tolerability and adherence. Pediatr Drugs, 2015; 17: 159-166

43) Humphries S, Cooper J, Dale P, Ramaswami U, FH Paediatric Register Steering Group. The UK Paediatric Familial Hypercholesterolaemia Register: Statin-related safety and 1-year growth data. J Clin Lipidol, 2018; 12: 25-32

44) Saltijeral A, Pérez de Isla L, Alonso R, Muñiz O, DíazDíaz JL, Fuentes F, Mata N, de Andrés R, Díaz-Soto G, Pastor J, Pinilla JM, Zambón D, Pinto X, Badimón L, Mata P; SAFEHEART Investigators. Attainment of LDL Cholesterol Treatment Goals in Children and Adolescents 
With Familial Hypercholesterolemia. The SAFEHEART Follow-up Registry. Rev Esp Cardiol, 2017; 70: 444-450

45) Banach M, Patti AM, Giglio RV, Cicero AFG, Atanasov AG, Bajraktari G, Bruckert E, Descamps O, Djuric DM, Ezhov M, Fras Z, von Haehling S, Katsiki N, Langlois M, Latkovskis G, Mancini GBJ, Mikhailidis DP, Mitchenko O, Moriarty PM, Muntner P, Nikolic D, Panagiotakos DB, Paragh G, Paulweber B, Pella D, Pitsavos C, Reiner $\check{Z}$, Rosano GMC, Rosenson RS, Rysz J, Sahebkar A, Serban MC, Vinereanu D, Vrablík M, Watts GF, Wong ND, Rizzo M; International Lipid Expert Panel (ILEP). The role of nutraceuticals in statin intolerant patients. J Am Coll Cardiol, 2018; 72: 96-118

46) Backes JM, Venero CV, Gibson CA, Ruisinger JF, Howard PA, Thompson PD, Moriarty PM. Effectiveness and tolerability of every-other-day rosuvastatin dosing in patients with prior statin intolerance. Ann Pharmacother, 2008; 42: 341-346

47) Ruisinger JF, Backes JM, Gibson CA, Moriarty PM. Once-a-week ro- suvastatin (2.5 to $20 \mathrm{mg}$ ) in patients with a previous statin intolerance. Am J Cardiol, 2009; 103: 393-394

48) Gadarla M, Kearns AK, Thompson PD. Efficacy of rosuvastatin $(5 \mathrm{mg}$ and $10 \mathrm{mg}$ ) twice a week in patients intolerant to daily statins. Am J Cardiol, 2008; 101: 1747-1748

49) Jacobson T, Khan A, Maki K, Brinton E, Cohen J. Provider recommendations for patients-reported muscle symptoms on statin therapy: Insights from the Understanding Statin Use in America and Gaps in Patient Education survey. J Clin Lipidol, 2018; 12: 78-88

50) Moriarty PM, Thompson PD, Cannon CP, Guyton JR, Bergeron J, Zieve FJ, Bruckert E, Jacobson TA, Kopecky SL, Baccara-Dinet MT, Du , Pordy R, Gipe DA, ODYSSEY ALTERNATIVE. efficacy and safety of the proprotein convertase subtilisin/kexin type 9 monoclonal antibody, alirocu- mab, versus ezetimibe, in patients with statin intolerance as defined by a placebo run-in and statin arm. Circulation, 2014; 130: 2108-2109

51) Stroes E, Colquhoun D, Sullivan D, Civeira F, Rosenson RS, Watts GF, Bruckert E, Cho L, Dent R, Knusel B, Xue A, Scott R, Wasserman SM, Rocco M; GAUSS-2 investigators. Anti-PCSK9 antibody effectively lowers cholesterol in patients with statin intolerance: the GAUSS-2 randomized, placebo-controlled phase 3 clinical trial of evolocumab. J Am Coll Cardiol, 2014; 63: 2541-2548

52) Ballantyne C, Banach M, Mancini J, Lepor N, Hansel- man J, Zhao X, Leiter L. Efficacy and safety of bempedoic acid added to ezetimibe in statin-intolerant patient with hypercholesterolemia: a randomized, placebo-controlled study. Atherosclerosis, 2018; 277: 195-203

53) Karalis DG, Wild RA, Maki KC, Gaskins R, Jacobson TA, Sponseller CA, Cohen JD. Gender differences in side effects and attitudes regarding statin use in the Understanding Statin Use in America and Gaps in Patient Education (USAGE) study. J Clin Lipidol, 2016; 10: 833-841

54) Roberts CG, Guallar E, Rodriguez A. Efficacy and safety of statin monotherapy in older adults. J Gerontol A Biol Sci Med Sci, 2017; 62: 879-887

55) Millan J, Pedro-Botet J, Climent E, Rius J, Statin Associated myopathy in clinical practice. Results of DAMA study. Clin Investig Arterioscler, 2017; 29: 7-12

56) Brinton EA, Maki KC, Jacobson TA, Sponseller CA, Cohen JD. Metabolic syndrome is associated with muscle symptoms among statin users. J Clin Lipidol, 2016; 10: 1022-1029

57) Michalska-Kasiczak M, Sahebkar A, Mikhailidis DP, Rysz J, Muntner P, Toth PP, Jones SR, Rizzo M, Kees Hovigh G, Farnier M, Moriarty PM, Bittner VA, Lip GY, Banach M, Lipid and Blood Pressure Meta-analysis Collaboration (LBPMC) Group. Analysis of vitamin D levels in patients with and without statin-associated myalgia - a systematic review and meta-analysis of 7 studies with 2420 patients. Int J Cardiol, 2015; 178: 111-116

58) Robinson CD, Bair TL, Horne BD, McCubrey RO, Lappe DL, Muhlestein JB, Anderson JL. Hypothyrodism as a risk factor for statin intolerance. J Clin Lipidol, 2014; 8: 401-407

59) Palmer S, Craig J, Navaneethan S, Tonelli M, Pellegrini F, Strippoli G. Benefits and harms of statin therapy for persons with chronic kidney disease: A systematic review and meta-analysis. Ann Intern Med, 2012; 157: 263-275

60) Kinoshita M, Yokote K, Ara, H, Iida M, Ishigaki Y, Ishibashi S, Umemoto S, Egusa G, Ohmura H, Okamura T, Kihara S, Koba S, Saito I, Shoji T, Daida H, Tsukamoto K, Deguchi J, Dohi S, Dobashi K, HAmaguchi H, Hara M, Hirot T, Biro S, Fujioka Y, Maruyama C, Miyamoto Y, Murakami Y, Yocode M, Yoshida H, Rakugi H, Wakatsuki A, Yamashita S, Committee for Epidemiology and Clinical Managelemt of Atherosclerosis. Japan Atherosclerosis Society (JAS) Guidelines for Prevention of Atherosclerotic Cardiovascular Diseases. J Atheroscler Thromb, 2018; 25: 846-984 